\title{
LA ÉTICA DEL CUIDADO EN SOCIEDADES GLOBALIZADAS: HACIA UNA CIUDADANÍA COSMOPOLITA $^{1}$
}

\section{THE ETHICS OF CARE IN GLOBALIZED SOCIETIES: TOWARDS A COSMOPOLITAN CITIZENSHIP}

\author{
Irene Comins $\mathrm{Mingol}^{2}$ \\ Universitat Jaume I (España)
}

Recibido: 30-11-2014

Aceptado: 02-02-2015

\begin{abstract}
Resumen: Este artículo aborda las contribuciones de una filosofía del cuidar a la construcción de una ciudadanía cosmopolita en un mundo globalizado. Y es que la capacidad del ser humano para empatizar con otros diversos, ser sensible a sus necesidades y responder adecuadamente va a jugar un papel fundamental en un mundo globalizado de interdependencias crecientes. Para ello el artículo aborda la importancia de una filosofía del cuidar para resignificar algunas asunciones dominantes sobre la naturaleza humana y señala el potencial de la ética del cuidado para tratar temas morales en contextos globales.

Palabras-clave: ética del cuidado, globalización, ciudadanía cosmopolita, paz, empatía.
\end{abstract}

\begin{abstract}
This article discusses the contributions of a philosophy of caring for the construction of a cosmopolitan citizenship in a globalized world. The human ability to empathize with diverse others, be sensitive to their needs and respond appropriately will play a key role in a globalized world of growing interdependences. The article addresses the importance of a philosophy of caring to challenge some key assumptions about human nature and points out the potential of the ethics of care to address moral issues in global contexts.

Key-words: care ethics, globalization, cosmopolitan citizenship, peace, empathy.
\end{abstract}

[1] Este estudio se inserta en el Proyecto de Investigación P1 1A2012-05 "De víctimas a indignados: visibilidad mediática, migración de imágenes, espectacularización de los conflictos y procesos de transformación social hacia una cultura de paz" financiado por la Universitat Jaume I de Castellón.

[2] (cominsi@uji.es) Profesora Contratada Doctora del Departamento de Filosofía y Sociología de la Universitat Jaume I, es investigadora de la Cátedra UNESCO de Filosofía para la Paz y del Instituto de Desarrollo Social y Paz de la misma universidad. Desde 2009 es codirectora del Máster Universitario en Estudios Internacionales de Paz, Conflictos y Desarrollo de la Universitat Jaume I. 


\section{Introducción}

Los procesos migratorios, las nuevas tecnologías de la comunicación, y en definitiva lo que viene a conocerse como globalización, están generando un cambio profundo en nuestras sociedades, haciendo que cada vez más nuestros proyectos vitales se entrecrucen radicalmente con los de otros seres humanos que hasta hace poco parecían lejanos, tanto física como conceptualmente. Muchas veces se trata de algo más que meros cruces hasta el punto que hoy más que nunca dependemos de personas que jamás hemos visto y que a su vez dependen de nosotros ${ }^{3}$. En este contexto parece cada vez más difícil sostener que las fronteras morales debieran coincidir con las fronteras de nuestra comunidad cotidiana. Aparece pues un interrogante, How far, literally, should we care $?^{4}$.

En este artículo vamos a abordar los desafíos y el potencial de la ética del cuidado en la construcción de una ciudadanía cosmopolita en un mundo globalizado. Y es que la capacidad del ser humano para empatizar con otros diversos, ser sensible a sus necesidades y responder adecuadamente va a jugar un papel fundamental en un mundo globalizado de interdependencias crecientes. Para ello el artículo se estructura en tres partes, en primer lugar se hace una breve presentación a la ética del cuidado, origen y contexto, en segundo lugar abordaremos la importancia de la ética del cuidado para cuestionar y resignificar algunas asunciones dominantes sobre la naturaleza humana. Finalmente señalaremos el revelador potencial de la ética del cuidado para tratar temas morales en contextos globales.

\section{La ética del cuidado: una breve presentación}

Carol Gilligan explicitó por primera vez en 1982 con su obra In a Different Voice, el diferente desarrollo moral que las mujeres han experimentado como resultado de la socialización y la práctica del cuidar. Hasta entonces la Teoría del Desarrollo Moral se ceñía sin excepciones a la teoría propuesta por su maestro y mentor Lawrence Kohlberg ${ }^{5}$. Gilligan intentó ampliar la teoría moral de Kohlberg incluyendo un análisis sobre las experiencias morales de las mujeres, ya que la teoría de Kohlberg se construyó exclusivamente sobre el estudio de varones, en concreto 84 niños varones durante un período de más de

[3] Nussbaum, M.: Sin fines de lucro. Por qué la democracia necesita de las humanidades. Madrid: Katz, 2010, p.113.

[4] Así reza el título del artículo publicado por D. M. Smith en 1998 en la revista Progress in Human Geography, 22 (1), 15-38, «How far should we care? On the spatial scope of beneficence».

[5] Kohlberg, L.: «Moral Stages and Moralization» en Lickona, T. (ed.): Moral Development and Behavior: Theory, Research and Social Issues. Nueva York: Rinehart and Winston, 1976.

THÉMATA. Revista de Filosofía, N52 julio-diciembre (2015) pp.: 159-178 doi: 10.12795/themata.2015.i52.09 
veinte años ${ }^{6}$. Otra de las anomalías que Gilligan detectó en la escala del desarrollo moral de Kohlberg fue la puntuación persistentemente baja de las mujeres al ser comparadas con sus iguales varones ${ }^{7}$. Ese desvío en la puntuación se debía lógicamente a que la teoría del desarrollo moral se había construido sólo tomando como base el estudio de la experiencia de hombres pero se aplicaba pretendiendo universalidad tanto a las mujeres como a los hombres. Gilligan detectó en su análisis de las mujeres una diferente voz moral más relacional, que situaba como preferente la preservación de las relaciones, en oposición con la ética de la justicia, de la teoría del desarrollo moral según Kohlberg, en la que se sitúa como preferente la obediencia a normas morales universales. Esa diferente perspectiva moral de las mujeres -señala claramente Gilligan- es resultado de la división sexual del trabajo y de la aguda división entre lo público y lo privado. Hombres y mujeres desarrollan así dos perspectivas morales distintas, en función de esa desigual atribución de responsabilidades, que se han venido a calificar como ética de la justicia y ética del cuidado.

Victoria Camps resume las características de la ética del cuidado en contraposición a la ética de la justicia de la siguiente manera: 1) Se trata de una ética relacional, donde lo que importa más que el deber es la relación con las personas. 2) No se limita a concebir la ley, sino que le interesa su aplicación situacional. 3) Considera que la racionalidad debe mezclarse con la emotividad. 4) Se centra en la implicación y compromiso directo y casi personal con los otros. 5) Añade un enfoque particularizado al enfoque abstracto y general de la ética de la justicia8.

La ética del cuidado eleva la atención, la responsividad ${ }^{9}$ y el mantenimiento de las relaciones interpersonales al estatus de una importancia moral fundacional. Pero no se queda únicamente al nivel privado, sino que rompiendo la dicotomía entre público y privado alcanza la reflexión política. Así, por ejemplo la teórica política Sevenhuijsen ${ }^{10}$, siguiendo el trabajo de Joan Tronto y otras, propone el concepto de ciudadanía cuidadora y argumenta que el cuidado debe reconciliarse con la justicia y las preocupaciones democráticas, por ello propone el cuidado como un tema de ciudadanía con importantes implicaciones prácticas y políticas.

[6] Cfr. Gilligan, C.: La moral y la teoría. Psicología del desarrollo femenino. México: Fondo de Cultura Económica, 1986 p. 40.

[7] Cfr. Benhabib, S.: «El otro generalizado y el otro concreto: la controversia Kohlberg-Gilligan y la teoría feminista» en Benhabib, S. y D. Cornel (eds.): Teoría feminista y teoría crítica. València: Edicions Alfons el Magnànim, pp. 119-149.

[8] Cfr. Camps, V.: El siglo de las mujeres. Madrid: Ediciones Cátedra, p. 69-81.

[9] Para un análisis del concepto de responsividad en Lévinas, Ricoeur y la ética del cuidado ver González Patiño, S.: La responsividad ética. Monterrey: Plaz y Valés, 2010.

[10] Sevenhuijsen, S.: The place of care. The relevance of the feminist ethic of care for social policy en Feminist Theory 4, n 2, 2003, pp. 179-197.

THÉMATA. Revista de Filosofía, $\mathrm{N}^{\circ} 52$ julio-diciembre (2015) pp.: 159-178 doi: 10.12795/themata.2015.i52.09 
En su recorrido la ética del cuidado ha sido también objeto de diferentes críticas. Una de esas críticas etiqueta la ética del cuidado de conservadora o incluso retrógrada, entre quienes piensan que refuerza los roles tradicionales de las mujeres como cuidadoras. Sin embargo Gilligan y otros autores muestran que la visión de la ética del cuidado como legitimadora de la subordinación tradicional de las mujeres está seriamente equivocada ${ }^{11}$. ¿Qué puede ser más revolucionario que desmontar la jerarquía de género del patriarcado en las formas más básicas de cómo pensamos que debemos vivir y qué debemos hacer? La ética del cuidado apela a la transformación de la sociedad, la política, las leyes, la actividad económica, la familia y las relaciones personales más allá de las asunciones del patriarcado. Como Gilligan expresa en su libro Joining the Resistance:

Our exploration has led us to see the ethic of care, grounded in voice and relationship, as an ethic of resistance both to injustice and to self-silencing. It is a human ethic, integral to the practice of democracy and to the functioning of a global society. More controversially, it is a feminist ethic, an ethic that guides the historic struggle to free democracy from patriarchy ${ }^{12}$.

Debido a las estructuras sociales existentes la gran parte del trabajo real de cuidados, en hogares e instituciones, se realiza por mujeres y es un trabajo no reconocido, gratuito o mal pagado. También cada vez más en los procesos migratorios, encontramos el trabajo de cuidados como uno de los trabajos ocupados por trabajadoras migrantes provenientes de países empobrecidos, que dejan sus familias durante años ${ }^{13}$.Una apropiada valoración del trabajo de cuidados subvertiría esta jerarquía que mantiene el cuidado en una situación marginal y de explotación.

\section{Hacia una visión renovada de la naturaleza humana}

Desde su formulación en 1982 el enfoque de la ética del cuidado ha sido ampliamente desarrollado por un gran número de filósofos y filósofas, siendo considerado, hoy en día, el enfoque alternativo más potente en cuestiones morales $^{14}$. Así mismo, ha contribuido significativamente, junto con otros desarro-

[11] Cfr. Richards, D.: Resisting Injustice and the Feminist Ethics of Care. New York: Routledge, 2013.

[12] Gilligan, C.: Joining the Resistance. Cambridge: Polity Press, 2013, p. 175.

[13] Cfr. Hochschild, A.: Global Woman: Nannies, Maids, and Sex Workers in the New Economy. New York: Routledge, 2003. Mahon, R. y Robinson, F.: Feminist Ethics and Social Policy: Towards a New Global Political Economy of Care. Vancouver: University of British Columbia Press, 2011. Vega Solís, C.: Culturas del Cuidado en Transición. Espacios, Sujetos e Imaginarios en una Sociedad de Migración. Barcelona: UOC, 2009.

[14] Held, V.: «The Ethics of Care as Normative Guidance: Comment on Gilligan» en Journal of Social Philosophy 45, ${ }^{\circ} 1,2014$, pp. 107-115.

THÉMATA. Revista de Filosofía, №52 julio-diciembre (2015) pp.: 159-178 doi: 10.12795/themata.2015.i52.09 
llos teóricos, a un cambio de paradigma en las ciencias humanas y sociales en virtud del cual se pone en valor y se reconoce la importancia de las relaciones, las emociones y la empatía ${ }^{15}$.

Esa diferente voz se escuchó por primera vez como "femenina» porque el patriarcado asoció las emociones y las relaciones con las mujeres, y las consideró respectivamente limitantes de su racionalidad y autonomía. Sin embargo lo que había sido considerado un problema en el desarrollo de las mujeres ha sido redefinido, desde la ética del cuidado, como un problema del marco interpretativo, como señala Gilligan «una limitación en la concepción de la condición humana, una omisión de ciertas verdades sobre la vida» ${ }^{16}$. Con el cambio de paradigma esa «diferente voz» se redescubre como una voz radicalmente humana.

Como señala $\mathrm{M}^{\mathrm{a}}$ Luz Pintos Peñaranda como humanos nacemos con unas capacidades pregenerizadas para la empatía, las emociones y la tolerancia, ${ }^{17}$ de ahí que la gran pregunta que cabe formularnos es, según Carol Gilligan, ¿Cómo perdemos esa capacidad para cuidar? ¿Qué inhibe nuestra habilidad de empatizar con otros? Para responder a esta pregunta Gilligan profundiza en el concepto de daño moral, que se produce con la ruptura de la confianza que compromete nuestra habilidad para amar. La ética del cuidado con su compromiso con las relaciones, el amor y la ciudadanía democrática, es también la ética de la resistencia al daño moral ${ }^{18}$.

En la adolescencia la construcción de la identidad se refuerza binariamente, de un modo en que la intimidad y la vulnerabilidad tienen un género, el femenino, y ser un hombre implica ser emocionalmente estoico e independiente $^{19}$. En When Boys Become Boys Judy Chu identifica este proceso a edades incluso más tempranas, en cómo los niños que en 4 y 5 años eran atentos, auténticos y directos en sus relaciones unos con otros inician un proceso de separación e inautenticidad. Según Chu no es que las capacidades relacionales de los chicos se hayan perdido sino que la socialización hacia la construcción cultural de la masculinidad, que es definida en oposición a la feminidad, parece forzar una división entre lo que los chicos saben y lo que los chicos muestran ${ }^{20}$. En las voces

[15] Un gran número de evidencias provenientes de la psicología evolutiva, la neurociencia o la primatología, entre otros campos, están arrojando una nueva luz sobre el concepto de naturaleza humana, y el importante papel que juegan las emociones y la empatía en el ser humano.

[16] Gilligan, C.: «Moral Injury and the Ethic of Care: Reframing the Conversation about Differences» en Journal of Social Philosophy 45, $\mathrm{n}^{\circ}$ 1, 2014, pp. 89-106. 89.

[17] Pintos Peñaranda, $M^{a}$ L.: «Fenomenología, Género y Paz» en Comins Mingol, I. y S. París Albert (eds.): Investigación para la paz. Estudios filosóficos. Barcelona: Icaria, 2010, pp.51-71.

[18] Gilligan, C.: Moral Injury... cit., p. 90.

[19] Ibidem, p.94.

[20] Chu, J.: When Boys Become Boys: Development, Relationships, and Masculinity. New York: New York University Press, 2014.

THÉMATA. Revista de Filosofía, $\mathrm{N}^{\circ} 52$ julio-diciembre (2015) pp.: 159-178 doi: 10.12795/themata.2015.i52.09 
de los adolescentes escuchamos señales del daño moral, en el momento en que son forzados, en virtud de la mística de la masculinidad, a traicionar lo que hasta ese momento consideraban correcto -la intimidad, la expresión del afecto y la sensibilidad-, una traición que es sancionada a los ojos del mundo como apropiada. En la historia del pensamiento occidental encontramos relatos simbólicos, y extremos, de esa traición al afecto y la intimidad. Agamenón sacrificando a su hija Ifigenia, Abraham preparándose para sacrificar a Isaac... actos en los que se traiciona el nexo íntimo de confianza filial en virtud de algún ideal superior, actos alabados culturalmente y recompensados con honor. La ética del cuidado como ética centrada en la vida y en su sostenibilidad, puede orientarnos en prevenir esa traición, ese daño moral. Ayudarnos a resignificar el concepto de ser humano, más allá de cualquier visión binaria o dicotómica entre géneros y a transgredir las construcciones identitarias violentas.

Quizás también el éxito de una cultura de paz dependa de que seamos capaces de reconciliarnos con nuestro interior y, muy modestamente, nos dejemos guiar por nuestras eficientes habilidades biológicas pre-racionales, que tan despectivamente solemos rechazar ${ }^{21}$.

Las observaciones de Gilligan cuestionan la validez de varias asunciones clásicas sobre el ser humano que adquirimos de nuestra cultura y tomamos como dadas, destacaremos aquí dos: la concepción negativa del ser humano y la idea de individuo autónomo.

a) ¿Una Antropología Negativa? Partiendo de la imagen del ser humano según Hobbes, somos individuos egoístas en búsqueda competitiva y permanente de poder. Esta asunción está en el fundamento de la mayoría de las teorías del contrato social en las que descansan los sistemas políticos liberales. Sin embargo las feministas han demostrado la distorsión de esta asunciones: sin cuidadores que actúan de un modo que contradice esas asunciones, ningún bebe habría crecido para ser un ser humano hobbesiano o un calculador racional. Diferentes antropólogos y primatólogos señalan también la importancia de la empatía en nuestra evolución y cómo junto con la cooperación juegan un papel fundamental en nuestra supervivencia como especie ${ }^{22}$. Para $\mathrm{M}^{\mathrm{a}}$ Luz Pintos

[21] Pintos Peñaranda, M ${ }^{a}$ L.: op. cit., p.71.

[22] El concepto de ser humano del que partimos tiene un gran poder para la construcción del futuro, pues como una profecía que se auto-cumple el ser humano construye su mundo según la expectativa que sobre el concepto de ser humano y de identidad su cultura dibuja, de ahí la importancia de clarificar nuestra noción de ser humano. Es importante analizar y redefinir el modelo antropológico dominante, ampliando el concepto reduccionista existente (focalizado en las competencias violentas-agresivas del ser humano) por un concepto más complejo (que reconozca también las competencias para hacer las paces que tienen todos los seres humanos). Puede consultarse un análisis interesante del papel que juega la definición de ser humano como profecía autocumplida en Fry, D.: The Human Potential for Peace: An Anthropological Challenge to Assumptions about War and Violence. Oxford: Oxford University Press, 2006.

THÉMATA. Revista de Filosofía, №52 julio-diciembre (2015) pp.: 159-178 doi: 10.12795/themata.2015.i52.09 
Peñaranda en la actuación positiva de las mujeres en los procesos de paz no interviene tanto nuestra cultura femenina como nuestra biología natural de animal humano.

Por nuestra propia biología, lo humanos ya estamos en una actitud de experiencia de vínculo, de comprensión y de tolerancia, que es natural y espontánea y, por tanto, que viene con nosotros de modo no racional ni premeditado y, por tanto, sin que medie ninguna construcción cultural ${ }^{23}$.

Las habilidades biológicas pre-generizadas de resolución de conflictos ${ }^{24}$ de las que nos habla $\mathrm{M}^{\mathrm{a}}$ Luz Pintos giran en torno a las emociones, la empatía y la tolerancia, las tres de elemental importancia en la experiencia de la alteridad. El ser humano, viene al mundo en un estado de desvalimiento más acentuado que el de otros seres vivos lo que hace que precise de esas habilidades y de sus congéneres para llegar a desarrollarse. "Son las culturas concretas [...] lo que en muchas ocasiones impide que obren las habilidades o estrategias adaptativas armonizadas ya inherentes a nuestra corporalidad biológica ${ }^{25}$.

b) ¿Individuos Autónomos? Otra de las asunciones con las que hemos definido desde occidente la naturaleza humana, y que bebe de la tradición kantiana y rawlsiana, es la del individuo racional autónomo en búsqueda de leyes abstractas y universales. Esta imagen distorsiona la realidad de cuán interdependientes y relacionales son los seres humanos que viven en contextos históricos concretos. Y cómo el cuidado vertebra lo que radicalmente somos, tal y como describe la fábula-mito de Higinio recuperada por Heidegger. Estas teorías olvidan la importancia para la moralidad de emociones como la empatía, la compasión, la indignación ante el sufrimiento, en breve, la importancia del cuidado. Si bien las teorías kantianas y rawlsianas reconocen que los sentimientos apropiados ayudan a llevar a cabo los dictados de la razón, excluyen dichos sentimientos de la posibilidad de jugar un rol epistemológicamente justificable en determinar lo que la moralidad recomienda. Consideran que sólo la razón provee ese motivo justificable y desconocen la importancia moral de las relaciones reales de cuidado. No tienen en cuenta la importancia de las emociones ni para la comprensión de qué debemos hacer ni en la motivación para realizar esas acciones moralmente recomendadas. Sin embargo, sin sensibilidad empática uno puede no ser capaz de satisfacer las necesidades de los otros en el modo que requiere la moralidad. Sin sentimientos de preocupación, uno puede no tomar la responsabilidad por responder aquellos que están en situación de necesidad. Para la ética del cuidado la moralidad no es tanto un

[23] Pintos Peñaranda, $\mathrm{M}^{\mathrm{a}}$ L.: op. cit., 55.

[24] Ibidem. 56.

[25] Ibídem. 70.

THÉMATA. Revista de Filosofía, Nº52 julio-diciembre (2015) pp.: 159-178 doi: 10.12795/themata.2015.i52.09 
tema de reconocimiento racional -que también- como, sobre todo, de asunción de responsabilidades por otras personas particulares necesitadas ${ }^{26}$. Esto cuestiona el mismo principio de imparcialidad, ya que para una buena relación de cuidado, necesitamos una comprensión moral contextual, narrativa y atenta a las particularidades.

Las observaciones de Gilligan nos permiten, pues, desafiar estas asunciones. Mientras que no son instalados en los hábitos del patriarcado, ni chicos ni chicas aspiran a ser ese individuo racional autosuficiente. Son, como todos nosotros, dependientes e interdependientes y conformados por, y a través de, sus relaciones con los otros. Las investigaciones de Gilligan muestran que es el patriarcado el que, en la adolescencia, lleva a las chicas a suprimir sus propias voces, y a los chicos a aspirar a la auto-suficiencia y al poder sobre otros. Sin el patriarcado, ambos estarían inclinados hacia la ética del cuidado tanto como a la ética de la justicia.

\section{Más allá de lo íntimo hacia lo global}

La ética del cuidado rechaza enérgicamente el confinamiento de sus valores a la esfera privada de las relaciones personales. La brecha entre lo público y lo privado y el confinamiento de las mujeres al último está en la base del patriarcado que la ética del cuidado trata de superar.

Dado el arraigo del lenguaje moral de los derechos y los deberes es difícil imaginar cómo, y en qué contextos, el lenguaje y las estrategias de una ética crítica del cuidado podrían ponerse en práctica. Autoras como Fiona Robinson señalan el modo en que el lenguaje moral de los derechos y los deberes está inextricablemente unido a la filosofía política del liberalismo, una filosofía que actualmente domina nuestra forma de pensar sobre economía política global, legitimidad internacional o desarrollo. El discurso moral de los derechos y deberes, que enfatiza una visión del ser humano como individuo autónomo y libre, la igualdad formal y la reciprocidad, es poco probable que incomode a las asimetrías en el poder y el bienestar que actualmente caracterizan el orden global. ${ }^{27}$ Acercar la ética del cuidado al ámbito público y al ámbito de las relaciones internacionales puede contribuir en el esbozo de un nuevo paradigma de cosmopolitismo, vamos a ver a continuación los ámbitos que puede contribuir a reformular:

[26] Held, V.: «The Ethics of Care as Normative Guidance: Comment on Gilligan» en Journal of Social Philosophy 45, ${ }^{\circ} 1,2014$, pp. 107-115.

[27] Robinson, F.: Globalizing Care. Ethics, Feminist Theory and International Relations. Oxford: Westview Press, 1999, p.157-158.

THÉMATA. Revista de Filosofía, N52 julio-diciembre (2015) pp.: 159-178 doi: 10.12795/themata.2015.i52.09 


\subsection{La atención a la diversidad: lo concreto dentro de lo universal}

En el camino hacia la construcción de una globalización humana ${ }^{28}$ debemos ser conscientes de la dialéctica entre la necesidad de una teoría de la justicia universalizable y al mismo tiempo la necesidad de reconocer las diferencias existentes entre los seres humanos. En este sentido la ética del cuidado tiene importantes contribuciones a realizar pues, como señala Gilligan, entre las habilidades cognitivas de esa diferente voz moral destacan dos: 1. El juicio moral de la ética del cuidar es más contextual, está más inmerso en los detalles de las relaciones. 2. Muestra mayor propensión a adoptar el punto de vista del «otro particular».

La contextualidad del juicio moral es una manifestación de madurez moral que considera al "yo como algo inmerso en una red de relaciones con los otros ${ }^{29}$. El respeto hacia las necesidades de los demás y la mutualidad del esfuerzo por satisfacerlas sustentan el crecimiento y el desarrollo moral. Desde el punto de vista del otro generalizado nuestra relación con la otredad se rige por las normas de igualdad formal y reciprocidad: cada cual tiene el derecho a esperar y suponer de nosotros lo que nosotros podemos esperar o suponer de él o ella. En cambio desde el punto de vista del otro concreto, nuestra relación está regida por las normas de equidad y reciprocidad complementaria: cada cual tiene el derecho a esperar y suponer de los otros y otras formas de conducta por las que ellos y ellas se sientan reconocidos y confirmados en tanto que seres individuales y concretos con necesidades y capacidades específicas. Aquí vemos la conexión entre la teoría del reconocimiento de Honneth y la noción de sujeto incardinado de Benhabib. Benhabib nos propone una teoría moral que nos permita reconocer la dignidad del otro generalizado mediante el reconocimiento de la identidad moral del otro concreto ${ }^{30}$.

En el camino hacia la construcción de una globalización humana es ineludible la tarea de reconstruir un sujeto arraigado, incardinado, un individuo con una historia, una identidad y una constitución afectivo-emocional concretas. También es importante proponer una nueva visión de las relaciones sociales. Un nuevo concepto de intersubjetividad en que, sobre la base imprescindible de una ética de la justicia, intentemos comprehender las necesidades de los otros y desarrollemos nuestra capacidad de empatía para entender sus motivaciones, qué busca y cuáles son sus deseos, lo cual es importante, entre

[28] U. Beck diferencia entre el globalismo o globalización económica vigente y la necesidad de construir una globalización humana. Ver Beck, U.: ¿Qué es la globalización? Buenos Aires: Paidós, 1998.

[29] Benhabib, S.: «El otro generalizado y el otro concreto: la controversia Kohlberg-Gilligan y la teoría feminista" en Benhabib, S. y D. Cornel (eds.): Teoría feminista y teoría crítica. València: Edicions Alfons el Magnànim, pp. 119-149, 121.

[30] Ibidem, p. 144.

THÉMATA. Revista de Filosofía, $\mathrm{N}^{\circ} 52$ julio-diciembre (2015) pp.: 159-178 doi: 10.12795/themata.2015.i52.09 
otras cosas, para una teoría del desarrollo. A ello nos puede ayudar la ética del cuidado y la teoría del reconocimiento, modulando la ética de la justicia.

No es a la idea de justicia a la que se opone la ética del cuidado, sino a la visión individualista y atómica de las personas como sujetos abstractos en lugar de $\operatorname{concretos}^{31}$. En definitiva el dilema entre la igualdad y la diferencia. Según Alison Jaggar:

La igualdad es parte integral de "una ética de la justicia» que es característicamente masculina en la medida que oscurece la diferencia humana abstrayéndola de la particularidad y singularidad de personas concretas en situaciones específicas y que intenta resolver los intereses conflictivos aplicando un poder abstracto, en lugar de responder directamente a las necesidades que se perciben inmediatamente ${ }^{32}$.

La ética del cuidado se preocupa por las necesidades de las personas más vulnerables e indefensas en contextos históricos concretos. Es por ello más sensible a la necesidad de mantener la paz, y evitar el conflicto violento, que aquellas teorías centradas en la justicia abstracta que pueden allanar el camino a la justificación de una intervención militar.

El reconocimiento de que las relaciones de cuidado existen y que pueden ser ampliadas abre nuevas posibilidades importantes para repensar las transformaciones necesarias para lidiar con la pobreza global y la reestructuración de la actividad económica. La ética del cuidado promueve el dialogo con, y la escucha de, otros cuyas experiencias, perspectivas y culturas son muy distantes a la nuestra.

Atenerse a los mismos principios en diferentes circunstancias puede ser una injusticia. Cuando nos aferramos a los principios, sin atender al contexto, no estamos teniendo en cuenta la complejidad. Ser sensible a un amplio rango de consideraciones morales puede ser a menudo más importante que la adherencia rígida a principios ${ }^{33}$. La teoría moral tradicional se ha basado frecuentemente en lo que una persona pensaría de estar en el punto de vista de un observador hipotético ideal. Sin embargo, la teoría feminista ha sido crítica de estos intentos de ignorar la realidad concreta y valora los juicios particulares producidos en la experiencia real sobre aquellos imaginados de ser aceptables en circunstancias hipotéticas ${ }^{34}$.

Podríamos calificar la ética del cuidado como ética dinámica en esa definición de Juan Masiá según la cual a la ética dinámica:

[31] Robinson, F.: Globalizing Care. Ethics, Feminist Theory and International Relations. Oxford: Westview Press, 1999, p.25.

[32] Jaggar, A.: «Ética feminista: algunos temas para los años noventa» en Castells, C. (ed.): Perspectivas Feministas en Teoría Política. Barcelona: Paidós, 1996.

[33] Held, V.: «Feminist Moral Inquiry and the Feminist Future», en HeLd, V. (ed.): Justice and Care: Essential Readings in Feminist Ethics. Colorado: Westview Press, 1995, p.162.

[34] Ibídem, p.160.

THÉMATA. Revista de Filosofía, N52 julio-diciembre (2015) pp.: 159-178 doi: 10.12795/themata.2015.i52.09 
se la busca, piensa y vive elaborándola junto con otras personas, a través de fallos y logros, ayudándose mutuamente a ponerse en órbita. En vez de una mera aplicación de normas y principios inmutables a casos concretos, se rehacen las normas y principios a la luz de cada caso inédito ${ }^{35}$.

\subsection{El poder de la motivación: de la teoría a la praxis}

Además de esta aportación a la ética de la justicia, la ética del cuidado también toma seriamente el problema de la motivación y el de la naturaleza de la respuesta moral, aspectos que son, en cierta medida, marginados por la ética de la justicia. En la ética de la justicia el concepto de deber se limita a la no-interferencia recíproca, en cambio, en la ética del cuidado incluye la necesidad de dar respuesta a las necesidades de los otros. Una de las diferencias más visibles de la ética del cuidado con respecto a otras es que no tiene como preocupación central el juicio moral. Para muchas otras éticas como la ética kantiana o la ética del discurso el juicio moral es el tema clave, ¿qué elementos hacen que un juicio sea moral? La mayoría de los filósofos que se han ocupado de la moral se han preguntado por el origen y fundamento de los juicios morales. Los juicios morales aprueban o desaprueban las conductas y actitudes humanas: aprobamos la generosidad y rechazamos el crimen. ¿En qué se fundan estos juicios? Para algunos en la razón, para otros en el diálogo, para otros en los sentimientos ${ }^{36}$. En cambio en la ética del cuidado toma preocupación central no sólo el juicio moral sino el impulso y la disposición moral ${ }^{37}$.

Según Adela Cortina uno de los grandes obstáculos a superar por el ámbito de la ética y la moral es la distancia existente entre nuestras grandes declaraciones sobre los derechos humanos y las realizaciones de la vida cotidiana, el abismo entre la teoría y la praxis ${ }^{38}$. En mi opinión, el cuidado supera este abismo ya que consiste en la aplicación afectiva y efectiva de los grandes principios morales a la realidad cotidiana. De este modo, el cuidado puede ser el puente que salve la distancia entre los grandes dichos y los hechos. El camino a través del cual los principios morales y los valores universales, se practiquen e incardinen en la cotidianidad.

[35] Masiá Clavel, J.: Fragilidad en Esperanza. Enfoques de Antropología. Bilbao: Desclée de Brouwer, 2004, p. 246.

[36] Hume fundamentó los juicios morales en el sentimiento, recogiendo una línea de pensamiento desarrollada en Inglaterra, en la primera mitad del s. XVIII, por filósofos moralistas como Shaftesbury (1671-1713) y Hutcheson (1694-1746).

[37] Noddings, N.: Caring: A Feminine Approach to Ethics and Moral Education. Berkeley: University of California Press, 1984, p. 28-29.

[38] Cortina, A.: Ética de la razón cordial. Educar en la ciudadanía en el siglo XXI. Oviedo: Ediciones Nobel.

THÉMATA. Revista de Filosofía, $\mathrm{N}^{\circ} 52$ julio-diciembre (2015) pp.: 159-178

doi: 10.12795/themata.2015.i52.09 
El filósofo Thomas Pogge, conocido por sus escritos sobre la pobreza global y las responsabilidades de los países más ricos, sitúa los derechos humanos en el centro de su análisis ${ }^{39}$. Según Pogge estamos violando los derechos humanos de los pobres del mundo al mantener un orden económico global que provoca esta pobreza. No obstante, los derechos humanos son elementos de la ley, son los mínimos que la ley debería asegurar. Y es que el hambre en el mundo no se presta bien a soluciones y remedios exclusivamente legales. La ética del cuidado, por el otro lado, clama para que algo se haga en favor de los niños y niñas que mueren cada año, de hambre o por una enfermedad evitable. El enfoque del cuidado podría proveer la motivación para abordar seriamente el problema ${ }^{40}$. El mismo Pogge reconoce que si la ciudadanía de los países más ricos se preocupara por reducir la pobreza global, también lo harían sus políticos y se tomarían los pasos necesarios al respecto ${ }^{41}$.

Sin embargo, la existencia cotidiana, especialmente la del mundo actual, tiende a aislar al ser humano y a transmitirle una impresión de irresponsabilidad $^{42}$. El alejamiento del individuo de los centros de poder o de la relación directa con el liderazgo, pueden generar lo que Weber llamaba alienación y Durkheim anomia, una situación en la que el compromiso con el sistema se atrofia y la iniciativa y la responsabilidad corren el riesgo de desaparecer ${ }^{43}$.

La participación requiere de una motivación, y un importante factor motivador es la preocupación por el bienestar de los seres humanos y de la naturaleza, y el reconocimiento de nuestras capacidades para ser agentes de cambio. La marginación y restricción del valor del cuidado a la esfera privada ha provocado nefastas consecuencias para la esfera pública. La falta de implicación, de compromiso, de motivación, de sentimiento de responsabilidad por lo que nos rodea son los más claros síntomas de este fenómeno. Erich Fromm señalaba, hace ahora ya más de medio siglo, como un peligro de nuestra sociedad «la insignificancia y pobreza del individuo». De ahí la importancia de reivindicar el cuidar para reconstruir los fundamentos de una ciudadanía participativa. Mediante las tareas de cuidado el individuo se siente significativo, importante, necesario, y se da cuenta de que tiene cierto poder para modificar la realidad. La participación responsable en las estructuras sociales constituye la mejor garantía para que el individuo pueda conseguir una vida buena y feliz. Así la democracia cumple con sus dos dimensiones: la instrumental, en cuanto método que permite resolver pacíficamente las disputas y exigir por

[39] Cfr. Pogge, T.: «¿Estamos violando los derechos humanos de los pobres del mundo?» en Eidos. Revista de Filosofía de la Universidad del Norte, 17, 2012.

[40] Held, V.: «The Ethics of Care...» cit., p. 113

[41] Pogge, T.: op. cit., 31.

[42] Ibídem p. 56.

[43] Ibídem p. 97.

THÉMATA. Revista de Filosofía, N 52 julio-diciembre (2015) pp.: 159-178 doi: 10.12795/themata.2015.i52.09 
parte de los ciudadanos a los gobernantes la satisfacción de sus necesidades; y la sustancial, en la medida en que esa participación política de los ciudadanos constituye una actividad humana intrínsecamente consustancial al desarrollo de las cualidades propias del ser humano.

De hecho el pensamiento que se desarrolla entre los teóricos del cuidar es altamente compatible con diferentes tendencias que se disciernen en el proceso de la globalización. Tales como el desarrollo de una sociedad civil global $^{44}$, el crecimiento de las organizaciones no gubernamentales o el nuevo orden mundial en red del que nos habla Anne-Marie Slaughter ${ }^{45}$. La "globalización desde abajo ${ }^{46}$ de los movimientos sociales transnacionales, tales como el movimiento ecologista o los movimientos contra los efectos nocivos de la globalización corporativa, apoyan el aumento de la influencia global del cuidado y de sus valores.

La ética del cuidado apoya claramente el derecho internacional, tal y como se ha desarrollado hasta ahora, pero apoya incluso más la cooperación cuidadosa que puede hacer decrecer la necesidad de dicha ley. ${ }^{47}$ Es interesante el concepto de ciudadanía glocal ${ }^{48}$, haciendo referencia al lema ecologista pensar global, actuar local.

El cuidado contribuye en el delineamiento del ejercicio de la ciudadanía como acción. Las democracias no se pueden reducir a su dimensión legal o al juego de mayorías y minorías. La alternativa pasa por reconstruir una democracia directa con una sociedad civil participativa con un abanico más amplio de opciones para la acción. En concreto, según Joan Tronto, Ruth Lister y Selma Sevenhuijsen, el cuidado como proceso social y práctica de una sociedad civil activa se desarrolla en tres fases que pueden resumirse así: 1. Ser sensibles y detectar las necesidades sociales de cuidado, 2. Asumir la responsabilidad y la potencialidad para ser agente de cambio, 3. Realizar las acciones pertinentes, es decir, materializar el cuidado. El cuidado, con esta estructura, sirve como base para el logro político de una sociedad mejor. En este sentido, Tronto propone una forma sencilla de definir la ciudadanía, como el proceso en el que los ciudadanos y ciudadanas se comprometen e involucran en procesos de cuidado. Una definición de ciudadanía que puede transformar el modo en que pensamos la vida pública y privada, el modo en que entendemos la participación política. De ahí la importancia de facilitar espacios, y tiempos, para

[44] Keane, J.: Global Civil Society? Cambridge: Cambridge University Press, 2003.

[45] Slaughter, A.M.: A New World Order. Princeton: Princeton University Press, 2004.

[46] Falk, R.: «The Making of Global Citizenship» en Brecher, J. y otros (eds.): Global Visions: Beyond the New World Order. Boston: South End Press, 1993.

[47] Held, V.: «Morality, Care...» cit.

[48] Ferrete, C.: «Ciudadanía sin límites: el trasfondo de la gobernanza global» en Quaderns de Filosofia i Ciència 41, 2011, pp.89-98, p.96.

THÉMATA. Revista de Filosofía, №52 julio-diciembre (2015) pp.: 159-178 doi: 10.12795/themata.2015.i52.09 
las prácticas de una ciudadanía cuidadora y responsable: prácticas en donde las personas pueden manifestarse a sí mismas como cuidadoras y/o receptoras del cuidado, en diálogo unas con otras, preocupadas por el bienestar propio, el de los otros y otras, y el de la naturaleza. Asistiendo así a nuevas formas de acción democrática que integran el cuidado como eje vectorial, convirtiéndose el cuidado en una práctica de política democrática participativa y global.

\subsubsection{Del deber de cuidar}

Según John Rawls la justicia es la primera virtud de las instituciones sociales ${ }^{49}$, pero autoras como Virgina Held sostienen que para lidiar con los problemas morales de un mundo cada vez más interconectado, una ética del cuidado desarrollado tendría más que ofrecer. Sarah Clark Miller examina el paradigma de la justicia hegemónico en el abordaje de los problemas morales y globales en la actualidad y defiende la necesidad de ponerlo en diálogo con las aportaciones de la ética del cuidado en lo que ella denomina un cuidado cosmopolita $^{50}$. Según Miller la distancia no es un factor de relevancia moral y propone un deber de cuidar que puede ser a la vez global y concreto en su respeto por formas locales de entender el cuidado. Según Clark Miller estamos moralmente obligados a responder a las necesidades fundamentales, tenemos el deber de cuidar. La conclusión de que tenemos un deber de cuidar descansa tanto sobre una ética kantiana y una ética del cuidado, de hecho Miller defiende una especie de hibridez entre la ética kantiana y la ética feminista del cuidado. La ética kantiana, y en concreto la idea del deber de ayudar, el principio de beneficencia, provee la fundamentación moral a la obligación de cuidar. Por otro lado, la ética del cuidado revela el contenido de esa obligación y la forma en la que debe llevarse a cabo. Miller establece un vínculo interesante entre el concepto kantiano de dignidad humana y el cuidado, un cuidado que refuerza la dignidad de las personas necesitadas. Según Miller se precisa una combinación de la ética kantiana y de la ética del cuidado para dar una explicación completa del deber de cuidar.

La ética del cuidado tomaría el derecho internacional, tal y como se ha desarrollado hasta ahora, como enormemente útil para evitar el conflicto violento. Pero no sólo eso, sino que lo entendería como expresión de los valores de cuidado y preocupación por la fragilidad de personas concretas ${ }^{51}$.

[49] Rawls, J.: A Theory of Justice. Cambridge, Harvard University Press, 1971.

[50] Cfr. Clark Miller, S.: The Ethics of Need: Agency, Dignity, and Obligation. New York, Routledge, 2012. Ver también su Tesis Doctoral: The Duty to Care. Need and Agency in Kantian and Feminist Ethics, 2003.

[51] Ídem.

THÉMATA. Revista de Filosofía, №52 julio-diciembre (2015) pp.: 159-178 doi: 10.12795/themata.2015.i52.09 
Todos reconocemos la importancia de elevar y promover el imperio de la ley al nivel global. Esto puede ser recomendado a partir de diferentes doctrinas morales, como la ética kantiana y el utilitarismo, pero puede ser incluso más fuertemente demandado por la ética del cuidado. Desde la perspectiva del cuidado, la ley es un enfoque limitado para un dominio limitado de la actividad humana. La ética del cuidado anima a los estados y otras organizaciones a tomar responsabilidades por proteger las poblaciones vulnerables y promover las regulaciones pacíficas de los conflictos antes de que escalen en violencia. La negociación de los conflictos no coercitivamente y el abordaje de los problemas de los políticamente marginados o explotados puede llegar a ser claramente prácticas de cuidado.

En lugar de centrarse en las normas a seguir o en las violaciones a la norma que deben penalizarse, la ética del cuidado atendería los problemas políticos, sociales y económicos que hacen que esas normas sean tantas veces inadecuadas en la protección de personas y grupos concretos.

\subsection{Un mundo de relaciones: más allá de la dicotomía entre cuidado y justicia.}

Las conexiones de la sociedad civil, más visibles en los últimos años, son fundamentales para la construcción de una sociedad más democrática y comprometida, y pueden ser interpretadas como relaciones de cuidado. Este cuidado debería ser gradualmente extendido a los habitantes del globo ${ }^{52}$.

La ética del cuidado, a diferencia de otras tradiciones éticas parte de una visión relacional e interdependiente de las personas. Mientras que la ética de la justicia prioriza los derechos individuales, buscando imparcialidad y principios universales, la ética del cuidado se centra en la confianza, los lazos sociales, la cooperación y la atención a las necesidades de los demás ${ }^{53}$.

El eje crucial se encuentra en la habilidad de pensar en las personas diferentes a nosotras como incluidas en la categoría de "nosotros». Para que ese compromiso empático tenga implicaciones en la calidad de la vida social colectiva es necesario reconciliar las tensiones entre la ética de la justicia y la ética del cuidado ${ }^{54}$. Una ética del cuidado reconceptualizada, que rechace la falsa dicotomía entre justicia y cuidado, puede tener implicaciones sustantivas para las vidas cotidianas de grupos marginalizados. La justicia está conectada con el cuidado, la solidaridad, la compasión y la empatía. A su vez el cuidado

[52] Held, V.: «The Ethics of Care...» cit., p. 113

[53] Zembylas, M. (2010): «The ethic of care in globalized societies: implications for citizenship education", Ethics and Education 5, n 3, 2010, pp. 233-245, 234.

[54] Smith, D.M.: Moral geographies, ethics in a world of difference. Edinburgh: Edinburgh University Press, 2000.

THÉMATA. Revista de Filosofía, №52 julio-diciembre (2015) pp.: 159-178 doi: 10.12795/themata.2015.i52.09 
nos ayuda a reconocer las obligaciones de justicia que tenemos con otros (independientemente de si se encuentran cerca o lejos de nosotros). El cuidado como práctica democrática ofrece un programa político que puede equilibrar los derechos y las responsabilidades.

La simbiosis entre la ética del cuidado y la ética de la justicia se aprecia de forma palpable en el hecho de que para transmitir el sentido de justicia de una generación a otra es necesario el amor y el cuidado hacia la infancia. Parecido argumento utiliza Susan Moller Okin para criticar la dicotomía entre la justicia y el cuidado ${ }^{55}$. Como especialista en Rawls, Okin argumenta que un correcto entendimiento de la teoría de Rawls debe incluir el reconocimiento de que para desarrollar el sentido de justicia los seres humanos deben ser criados y socializados en un ambiente que desarrolle sus mejores capacidades. Según Okin la posición de Rawls, normalmente criticada de individualista y abstracta, tiene como centro una voz de responsabilidad, cuidado y preocupación por otros.

El problema radica en la incapacidad de ponerse en el lugar de otros seres humanos que viven cotidianamente sin oportunidades de superación, simplemente porque están lejos de nosotros ya sea conceptual o geográficamente. ${ }^{56}$

Julian Huxley creía que la espiral ascendente de la evolución humana está orientada hacia la complejidad, el pensamiento planetario y el desarrollo integral de todos. Según Leonardo Boff hay razones para la esperanza, que nos permiten vislumbrar en el horizonte la transición hacia una autoconciencia global. Boff resume en cinco los grandes momentos de la historia universal y humana ${ }^{57}$ : Cósmico: el universo en proceso de expansión irrumpe en el escenario, nosotros estábamos ahí, en las posibilidades contenidas en ese proceso. Químico: a medida que se fueron densificando los diferentes cuerpos celestes se formaron los elementos que constituyen cada uno de los seres, el oxígeno, el carbono, el nitrógeno y otros; los mismos elementos químicos que circulan por nuestro cuerpo. Biológico: hace aproximadamente unos 3.800 millones de años surgió la vida en la Tierra. Humano: hace 10 millones de años aparece el ser humano, que ha sometido a todas las demás especies, -a excepción de la mayoría de los virus y de las bacterias-; se trata del peligroso triunfo de la especie homo sapiens y demens. Planetario: la humanidad se descubre a sí misma con el mismo origen y el mismo destino que todos los demás seres y que la Tierra, aparece una nueva autoconciencia.

[55] Robinson, F.: Globalizing Care. Ethics, Feminist Theory and International Relations. Oxford: Westview Press, 1999, p.24.

[56] Mayor Zaragoza, F.: La nueva página. París: UNESCO, p. 153.

[57] Boff, L.: El cuidado esencial. Ética de lo humano, compasión por la Tierra. Madrid: Trotta, 2002, p. 59-60.

THÉMATA. Revista de Filosofía, №52 julio-diciembre (2015) pp.: 159-178 doi: 10.12795/themata.2015.i52.09 
La vida exige un gran caudal de amor, dirigido incluso a seres tan alejados de nuestra experiencia cotidiana que es menester un esfuerzo consciente para recordar su existencia, su co-existencia.

La ética del cuidado en lugar de basarse en un modelo de individuo independiente y autosuficiente, concibe a las personas como inherentemente relacionales e interdependientes. En lugar de asumir que las relaciones sociales moralmente relevantes son las que iniciamos voluntariamente, reconoce la significatividad moral de las relaciones no escogidas entre personas de poder muy desigual en las que nos encontramos ${ }^{58}$. La ética del cuidado fomenta prácticas como la construcción de confianza, la atención a necesidades reales y el abordaje de los conflictos de forma noviolenta.

¿Es ciertamente la distancia -física/espacial, cultural y psicológica entre los agentes morales- lo que debemos abordar y ajustar al pensar en una ética global o internacional ${ }^{59}$. Según los teóricos de la globalización y del cambio social global, el orden del mundo contemporáneo se caracteriza por su profundo cambio en lo que a distancias se refiere ${ }^{60}$. La noción del encogimiento del mundo sugiere que de alguna forma las distancias se han reducido. El resultado es la creación de relaciones entre otros ausentes, localmente distantes para una situación de interacción cara a cara; a través de los medios de comunicación, el transporte o las tecnologías de la información. Una era de globalización caracterizada también por diferencias radicales, percepciones de las diferencias afectadas por las relaciones de poder y patrones de exclusión. Según Fiona Robinson una ética para esta era no puede mantenerse en la distancia, adoptar un punto de vista desde ningún lugar, o mantenerse tras el velo de ignorancia, viendo los actores globales como participantes autónomos e iguales en relaciones políticas, económicas y morales ${ }^{61}$.

Una era de interdependencia global demanda una ética relacional que sitúe el valor más elevado en la promoción, restauración o creación de buenas relaciones sociales y personales, y de prioridad a las necesidades e intereses de otros concretos ${ }^{62}$. Según Fiona Robinson la aportación principal de la ética del cuidado a las relaciones internacionales es el énfasis en la creación de nuevas relaciones sociales e incluso personales entre grupos e individuos de diferentes niveles socio-económicos y lugares. Esas nuevas relaciones pueden motivar atención moral y cuidado.

[58] Held, V.: «Morality, Care and International Law》en Ethics \& Global Politics 4, n 3, 2011, pp.173-194.

[59] Robinson, F.: Globalizing Care. Ethics, Feminist Theory and International Relations. Oxford: Westview Press, 1999, p.44-45.

[60] Ibídem, p. 45.

[61] Ibidem, p. 46.

[62] Ídem.

THÉMATA. Revista de Filosofía, $\mathrm{N}^{\circ} 52$ julio-diciembre (2015) pp.: 159-178 doi: 10.12795/themata.2015.i52.09 
Frente a las políticas del miedo que se erigen en occidente como visión de la otredad, las políticas del cuidado. El miedo a los bárbaros -así reza el título de uno de los últimos libros de Tódorov ${ }^{63}$ - es el que amenaza en convertirnos en bárbaros a nosotros mismos. La ética del cuidado, centrada en la vida, puede ayudarnos a cambiar de orientación respecto a la visión de la otredad.

La ética del cuidado en la que se socializan las mujeres tiene como eje prioritario de la acción moral el sostenimiento y no ruptura de las relaciones interpersonales. En contraste la ética de la justicia tiene como eje prioritario de la acción moral el cumplimiento de los principios universales abstractos, si es necesario a costa de las mismas relaciones interpersonales -llegándose a justificar bajo la bandera de la libertad, la igualdad o cualquier otro principio universal, la guerra y la destrucción de vidas humanas, consideradas meros efectos colaterales-. Así pues, el sujeto, desde el punto de vista de la ética del cuidar, es un sujeto intrínsecamente relacional, que tiene en el sostenimiento de la vida y la interconexión con los otros el eje prioritario de la acción moral. Annette Baier ha comparado la crítica de Gilligan a la autonomía y desarraigo del individuo con el lenguaje marxista de la alienación. El trabajo en la fábrica capitalista aliena al trabajador al desconectarlo del producto de su trabajo. La ética de la justicia aliena moralmente al individuo al separarlo de su mayor fuente de moralidad: la interconexión con los otros. Según Baier algunos de los efectos de esta falta de interconexión son la soledad, la apatía para la participación en procesos políticos o la falta de sentido de la vida. La madurez moral de la ética del cuidado implica una ciudadanía más comprometida, responsable e interconectada. Si bien uno de los grandes logros de la modernidad fue el descubrimiento de la autonomía, ese logro degeneró en las sociedades modernas en un excesivo individualismo. Un individualismo que implicaba la inflación de los derechos individuales, sin referencia alguna a los deberes, y la pérdida de sentido de pertenencia a una comunidad. Desde la ética del cuidado se viene realizando una crítica de ese individualismo abstracto. Un individualismo que menosprecia el papel de las relaciones sociales en la constitución de la auténtica identidad y la naturaleza de los seres humanos. Los sujetos del individualismo abstracto se presentan como maximizadores utilitaristas que buscan racionalmente su propio interés y beneficio. Frente a esa concepción individualista y abstracta del yo y de la comunidad humana, desde la ética del cuidado se propone una concepción del yo como algo inherentemente social. El conflicto y la competición ya no se consideran las relaciones humanas básicas, sino que se sustituyen por visiones alternativas de la fundación de la sociedad humana derivadas del apego del cuidado y la atención.

[63] Tódorov, T.: El miedo a los bárbaros. Barcelona: Galaxia Gutenberg, 2014. Tódorov utiliza el concepto barbarie para designar la capacidad humana de despreciar la humanidad de los otros, en contraste con el de civilización, que designaría la capacidad para considerar la humanidad del otro.

THÉMATA. Revista de Filosofía, N52 julio-diciembre (2015) pp.: 159-178 doi: 10.12795/themata.2015.i52.09 
Los valores cívicos tradicionales de justicia, igualdad y libertad constituyen un mínimo necesario, pero no suficiente, para conseguir una democracia participativa. La tarea pendiente consiste en reconstruir el paradigma de una ciudadanía democrática a través del desarrollo de un nuevo lenguaje capaz de incorporar valores relacionales. El concepto de ser humano inherente a la ética del cuidado diverge del concepto de individualismo unilateral de muchas teorías políticas. La interrelación y la interdependencia son conceptos centrales en una ética del cuidar. El pensamiento que guía la ética del cuidar es el de seres humanos necesitados unos de otros en el objetivo de conseguir una vida de calidad, y que sólo pueden desarrollarse como individuos a través de relaciones de cuidado con los otros. Selma Sevenhuijsen acuñó este fenómeno de autonomía relacional. Así, desde la ética del cuidado la relación y la interdependencia entre los seres humanos son la red fundamental sobre la que se basa nuestro accionar y nuestro posicionarnos en el mundo.

\section{Conclusiones}

Como hemos visto, la justicia y el cuidado son interdependientes y ambos son necesarios en la construcción de una globalización humana. Pero si bien la ética del cuidado no pretende sustituir la ética de la justicia, puede aportarle elementos de valor, como la consideración del otro concreto o la importancia de la respuesta moral.

De las muchas críticas a la modernidad occidental que se han realizado, Bauman nos ayuda a tomar conciencia de los «residuos humanos» que estamos creando en el orden mundial tal como lo estamos configurando: vidas desperdiciadas, basura, parias ${ }^{64}$. Sólo tenemos que pensar en la gente que muere en las pateras o en los inmigrantes que consideramos ilegales. Tódorov en El miedo a los bárbaros nos advierte del peligroso lugar al que nos conducen las políticas del miedo, a convertirnos en bárbaros, siguiendo el dicho «ya hemos encontrado al enemigo. Somos nosotros mismos».

Como nos advertía Kant el ser humano tiene el gran potencial de construir su propio carácter «al ser capaz de perfeccionarse de acuerdo con los fines que él mismo se señala» ${ }^{65}$, esa es la esperanza que nos anima a proponer la educación en los valores y praxis del cuidar como parte de una educación para una ciudadanía cosmopolita. El sistema de seguridad basado en el miedo a la diferencia, a la otra/o, construida/o como enemiga/o y convertida/o en alguien a dominar, está en el origen de la organización mundial en estados nación militarizados, creando la cultura de la guerra, entre los seres

[64] Bauman, Z.: Vidas desperdiciadas. La modernidad y sus parias. Barcelona: Paidós, 2005.

[65] Kant, I.: Antropología en sentido pragmático. Madrid: Revista de Occidente, 1935 p. 221.

THÉMATA. Revista de Filosofía, Nº52 julio-diciembre (2015) pp.: 159-178 doi: 10.12795/themata.2015.i52.09 
humanos ${ }^{66}$. Como señala Mary Brabeck el ideal moral incluye responsabilidad hacia los otros, conexión y compasión, factores que no se encuentran en el margen de la moralidad sino en su mismo centro ${ }^{67}$. Implicaría un cambio en el concepto de educación para la ciudadanía, que añadiría la maduración emocional. Educar en la madurez moral, desde Gilligan significa educar en la madurez tanto de la justicia, como de la preocupación y cuidado de unos seres humanos por otros ${ }^{68}$.

[66] Martínez Guzmán, V.: "Género, paz y discurso», en Fisas, V. (ed.): El sexo de la violencia. Género y cultura de la violencia. Barcelona: Icaria, 1998, p. 121.

[67] Brabeck, M.M.: Who cares? Theory, Research, and Educational Implications of the Ethic of Care. New York: Praeger, 1989.

[68] Martínez Guzmán, V.: «Género, paz y discurso», en Fisas, V. (ed.): El sexo de la violencia. Género y cultura de la violencia. Barcelona: Icaria, 1998, p. 123. 